\title{
Targeted Therapy in Oncology
}

\author{
BK Mishra*, Purvish M. Parikh ${ }^{+}$
}

MJAFI 2006; 62 : 169-173

Key Words : Targeted therapy; Oncology

\section{Introduction}

C ancer incidence is increasing worldwide. New cases have an increasing tendency to be concentrated in developing countries, WHO estimating that $66 \%$ of all new cases will be diagnosed within such regions. Also the majority of patients are diagnosed in advanced stage, requiring systemic therapy. Hence chemotherapy has been the traditional mainstay of treatment for such patients. Unfortunately such therapy acts in a non specific manner, resulting in significant toxicity. Therefore there has been an urgent need to find alternate avenues of management for such patients. Advances in understanding the biology of cancer cells and their metabolic functioning have led to the recognition of several molecule and processes that are unique to the cancerous cells. Over the last few years, these have been (successfully in several instances) explored as potential targets for cancer directed therapy.

This gave birth to the era of targeted therapy. Targeted therapy is defined as a drug or molecule causing tumour cell kill by interacting with predefined target(s) present on malignant cells. Such an approach has obvious advantages. The most important being that it would selectively attack the cell surface molecules, signalling of metabolic pathways that are unique to the malignant cells. This has the potential to spare the normal cells, thereby reducing toxicity and improving quality of life while continuing to have greater efficacy.

Types of targeted therapy: Depending on the mode of action and the specific "targets", various agents can be classified in sub-categories. Some of the important ones are Monoclonal antibodies, Tyrosine Kinase Inhibitors, Proteasome inhibitors, Cyclin-Dependent Kinase (CDK) Inhibitors, Raf Kinase Inhibitors, Antiangiogenic agents, Matrix Metalloproteinase Inhibitors Farnesyltransferase Inhibitors, Protein Kinase C Inhibitors, Glutathion-S-transferase Inhibitors, Histone Deacetylase Inhibitors, Cox-2 inhibitors, Antisense
Technology and Gene Therapy. Important targeted therapy molecules which are currently approved for human use are listed in Table 1.

Table 1

Important targeted therapy drugs approved for human use

\begin{tabular}{|c|c|c|}
\hline Name & Target & Indication \\
\hline Rituximab & CD20 & Non-Hodgkin lymphoma \\
\hline Trastuzumab & HER/neu & Breast cancer \\
\hline $\begin{array}{l}\text { Gemtuzumab } \\
\text { ozogamicin }\end{array}$ & CD33 & Acute myeloid leukemia \\
\hline Alemtuzumab & CD52 & $\begin{array}{l}\text { Chronic lymphocytic } \\
\text { leukemia }\end{array}$ \\
\hline Ibritumomab tiuxetan & CD20 & Non-Hodgkin lymphoma \\
\hline Bevacizumab & VEGF & Colorectal cancer \\
\hline Bortezomib & Proteasome & Multiple myeloma \\
\hline Cetuximab & EGF receptor & Colorectal cancer \\
\hline Gefitinib & Tyrosine kinase & $\begin{array}{l}\text { Non small cell lung } \\
\text { cancer }\end{array}$ \\
\hline Imatinib & Tyrosine kinase & $\begin{array}{l}\text { Chronic myeloid } \\
\text { leukemia }\end{array}$ \\
\hline Tositumomab & $\mathrm{CD} 20$ & Non-Hodgkin lymphoma \\
\hline Sorafenib & $\begin{array}{l}\text { Serine/threonine } \\
\text { and receptor } \\
\text { tyrosine kinases }\end{array}$ & $\begin{array}{l}\text { Advanced renal cell } \\
\text { carcinoma }\end{array}$ \\
\hline Sunitinib maleate & $\begin{array}{l}\text { Multiple kinases } \\
\text { receptors }\end{array}$ & $\begin{array}{l}\text { Gastrointestinal stromal } \\
\text { tumour, advanced renal } \\
\text { cell carcinoma }\end{array}$ \\
\hline
\end{tabular}

According to their mechanism of action, targeted therapy molecules can be classified into following categories:

1. Monoclonal antibodies: It was G. Kohler and C. Milstein [1] in 1975 who developed the hybridoma technology which provides monoclonal antibodies (MAbs) capable of highly specific associations with their target antigens. They produce hybrid cell lines by fusing antibody-producing cells from immunized mice with antibody-secreting mouse cells derived from myeloma and spleen cells. These hybrid cell lines can be cloned and cultured indefinitely. Because of this technology it was possible to produce large amount of individual antibodies. In 
1984, both scientists were honoured with the Nobel Prize for their work. MAbs were instantly applicable in diagnosis. However therapeutic use was fought with problems. When these antibodies, produce in mice cell lines, were injected in human they were quickly recognized as foreign proteins and rejected by auto-antibodies, some times even causing serious allergic reactions. It took time for such problems to be tackled. Now it is possible to produce chimeric and humanized mAbs that are therapeutically effective.

MAbs mediate their action via variety of mechanisms, and some pathways that are still poorly understood. Some of the known mechanisms include Antibody dependent cellular cytotoxicity (ADCC), Complement-dependent cytotoxicity(CDC), Signal transduction changes, Immunomodulation [2,3] and delivery of cytotoxic payloads (as transport vehicle for other agents) [4].

2. Tyrosine Kinase Inhibitors: Tyrosine kinases are group of enzymes which are responsible for cellular proliferation, survival, differentiation, function, and motility. After successful invention of imatinib, these are considered as excellent targets for the development of anti cancer therapy. Some of the clinically important types of tyrosine kinases are epidermal growth factor receptor, platelet derived growth factor receptor, vascular endothelial growth factor receptor, and cytosolic Abelson tyrosine kinase.

Examples-Imatinib Mesylate (STI571), Gefitinib (ZD1839), Erlotinib (OSI-774), CI-1033, EKB-569, etc.

3. Proteasome inhibitors: Proteasome is an enzyme complex that is responsible for the degradation of intracellular proteins, including several involved in cell cycle control and the regulation of apoptosis. Bortezomib is the most important proteosome inhibitor, which is used for the treatment of multiple myeloma. Trials are undergoing for its possible role in leukemia, Waldenstrom Macroglobulinemia, malignant lymphoma, and several solid tumour types. Example - bortezomib (Velcade).

4. Cyclin-Dependent Kinase (CDK) Inhibitors: CDK inhibitors are able to produce cell cycle arrest and induce apoptosis. Example- flavopiridol (HMR1275) is found to be active in colon cancers, NSCLC and ovarian cancer either as a single agent or in combination with chemotherapeutic agents.

5. Raf Kinase Inhibitors: Raf kinase inhibitors interfere with mechanism of production of Ras. Example-
Sorafenib (BAY 43-9006) found to be effective in renal cell carcinoma

6. Antiangiogenic agents: Initially tumour growth depends upon its host for its blood supply. But for growing beyond a certain size, angiogenesis is required. Many local as well genetic alterations are responsible for angiogenesis by upregulating vascular endothelial growth factor (VEGF) or downregulating thrombospondin-1 (TSP-1; a naturally occurring angiogenesis inhibitor). Agents that inhibit the angiogenesis process may play important role in tumour regression and kill.

a. VEGF inhibitors: Various VEGF inhibitors that are in use or under clinical trials are SU5416 (Semaxanib) for various advanced malignancies and ZD6474 for NSCLC.

b. Anti-VEGF and VEGFR Antibodies: Bevacizumab is the most important agent in this group. It is approved for the treatment of colon cancer and is under trial for other malignancies like gastric and lung cancer.

7. Matrix Metalloproteinase Inhibitors: Matrix Metalloproteinases(MMP) are responsible for degradation of the basement membrane and the extracellular matrix, which help in tumour growth, invasion, and spread. Important MMP inhibitors which are under trials are Marimastat ( recurrent GBM and anaplastic gliomas), Metastat (recurrent high-grade gliomas) \& Prinomastat ( NSCLC \& GBM).

8. Farnesyl Transferase Inhibitors: Farnesyl transferase inhibitors (FTIs), act through competitive inhibition of farnesyl protein transferase. Farnesyl transferase is the critical enzyme responsible for the production of intracellular substrate proteins such as Ras. These agents are found to have an important role in the treatment of myeloid malignancies. ExampleTipifarnib (R115777)

9. Protein Kinase C Inhibitors: Protein kinase C (PKC) family of enzymes mediate signals from the cell surface to the nucleus and play a key role in cellular signalling pathways produced by variety of extracellular stimuli, like growth factors, hormones, and neurotransmitters. One of the important PKC inhibitor is Enzastaurin which is under phase-II trial for therapy of NSCLC.

10. Glutathion-S-transferase Inhibition: Glutathion-Stransferase (GST) P1-1 play role in chemotherapy resistance and may be over expressed in many malignancies. GST inhibitors preferentially targets chemotherapy resistant cells. One example of these 
agents is TLK286 which showed activity in NSCLC [5] and now under phase- III trial.

11. Histone Deacetylase Inhibitors: Histone deacetylase (HDAC) inhibitors act as antiproliferative agents by upregulation of tumour suppressor genes. Various trials [6] are ongoing to find out their activity in solid and haematological malignancies. It is also found to modulate effect of radiation response to tumour [7].

12. Retinoids: Alteration of retinoid X receptors (RXR) expression is found in various solid and lymphoid tumours. RXR is responsible for regulation of proliferation and differentiation. Example of $\mathrm{X}$ receptor-specific retinoid with anti-tumour activity is Bexarotene which is approved for cutaneous $\mathrm{T}$ cell lymphoma. In one study it showed an overall response rate of $44.4 \%$ when used as a second line therapy [8].

13. COX-2 Inhibitors: Cyclooxygenase-2 (COX-2), is a the rate-limiting enzyme of the prostaglandin cascade. Its activity is related to mutagenesis, mitogenesis, angiogenesis, and deregulation of apoptosis of tumour cells. COX-2 inhibitors are found to be active as preventive agents, in combination with chemotherapy agents and also as radiosensitizers[9]. Unfortunately its potential for causing death due to cardiotoxicity is a major setback.

14. Antisense Technology: Various Antisense oligonucleotides are under evaluation for their role as antineoplastic agents in a series of clinical trials. G3139, a phosphorothioate oligomer which targets the initiation codon region of the bcl-2 mRNA is under evaluation for advanced melanoma, myeloma, and chronic lymphocytic leukemia (CLL).

15. Gene Therapy: Gene therapy is another prospective cancer targeted therapy. Clinical trials are ongoing or have been planned in carcinoma prostate, carcinoma breast, glioblastoma multiforme, malignant melanoma \& NSCLC. The main technical problem faced in gene therapy is to find a safe and efficient vector technology for gene transfer. In NSCLC intramural injection of recombinant adenovirus expressing wild type p53 produced response rate of $8 \%$ [10]. Recently, a gene therapy system has received marketing approval in China - the first such approval globally.

Clinical Application of specific Targeted Therapy for Hematological Malignancies \& Solid Tumours

Rituximab: Rituximab was approved in 1997 for treatment of non-Hodgkin lymphoma expressing CD20 surface receptor. It induces apoptosis, antibodydependent cell cytotoxicity, and complement-mediated cytotoxicity [11]. The update results of GELA trial [12] showed a 5-year event free survival reported of $47.6 \%$ in $\mathrm{R}-\mathrm{CHOP}$ arm versus $28 \%$ in $\mathrm{CHOP}$ arm $(\mathrm{P}$ values $=$ $0.00002)$. It further showed benefit in progression free survival, disease-free survival, and overall survival in favour of R-CHOP arm with P values of 0.00001 , 0.00031 , and 0.0073 , respectively. Rituximab has also been found to be beneficial in other haematological disorders like chronic lymphocytic leukaemia, multiple myeloma, hairy cell leukaemia and Waldenstrom Macroglobulinemia.

Gemtuzumab ozogamicin: Gemtuzumab ozogamicin was approved in 2000 for treatment of Acute Myeloid Leukemia. It targets CD33 surface receptor expressed by $90 \%$ of myeloid leukaemic blasts but absent on normal cells. Gemtuzumab linked with a molecule calicheamicin, which is a potent cytotoxic antibiotic, can augment inhibition of DNA synthesis and induction of apoptosis. In spite of its potential myelosuppressive and hepatic toxicity, in relapse AML it showed $33 \%$ overall response rate [13]. Results of phase 2 studies may be able to answer questions regarding its role as combination with other chemotherapeutic agents.

Alemtuzumab: It was approved in 2001 for treatment of B-cell chronic lymphocytic leukaemia expressing CD52 surface receptor. In one trial, in 93 fludarabinerefractory patients, it showed overall objective response of $33 \%$, with $2 \%$ complete remission and $31 \%$ partial remission. The median time to progression for responders was 9.5 months [14]. It can also be used as front line therapy, where response rates are expected to be higher as compare to its use in refractory patients [15].

$\mathrm{Y}^{90}$-Ibritumomab Tiuxetan: In 2002, this became the first radioconjugated antibody approved for treatment. It is found active in relapsed or refractory low grade and follicular B-cell non-Hodgkin lymphoma and also active in rituximab refractory disease. It showed a $73 \%$ to $83 \%$ overall response rate in various published studies and providing new hope in refractory patients [16].

Tositumomab: A radiolabeled anti-CD20 murine monoclonal antibody, this was approved in 2003 for treatment of relapsed and refractory follicular/low-grade and transformed non-Hodgkin lymphoma. In a combined report of five clinical trials, the response rate was $47 \%$ to $68 \%$; complete response rates ranged from $20 \%$ to $38 \%$. With a median follow-up of 5.3 years, the 5 -year progression-free survival reported was $17 \%$ [17].

Imatinib Mesylate: This is now established as a drug of choice for CML patients who are unable to undergo allogenic stem cell transplant. It is also approved for 
treatment of relapsed and metastatic gastrointestinal stromal tumours. It inhibits protein tyrosine kinases, bcrabl abnormal fusion protein in CML and c-kit (CD117) in gastrointestinal stromal tumours. The only concern seems to be the emergence of imatinib resistance usually caused by mutations [18].

Bortezomib: Bortezomib, a proteosome inhibitor, approved in 2003 for use in multiple myeloma for patients who had received at least two prior therapies and had demonstrated progression of disease on their last therapy. It is now used in both refractory setting and denovo patients usually before autologous stem cell transplant. A comparative phase III trial of bortezomib versus high dose dexamethasone showed statistically significant difference in time to disease progression and survival benefit - in favour of patients who received bortezomib [19].

Trastuzumab: Trastuzumab, a humanized monoclonal antibody, inhibits cell growth by binding to HER 2 protein tyrosine kinase receptor present in breast tumour cells. In a phase 3 trial the response rate in combination therapy was found to be $50 \%$ versus $32 \%$ for chemotherapy alone [20]. After establishing its role in the metastatic setting, trastuzumab actively is now also proven for adjuvant therapy in early breast cancer.

Gefitinib: Gefitinib received approval in 2003 for its use as a third-line treatment for non-small cell lung cancer. Two large phase-II trials, IDEALs 1 and 2, were conducted in patients previously treated with one or more chemotherapy regimens [21,22] These showed response rates in the range of 9 to19\%, comparing favourably with $7 \%$ for docetaxel. It was also observed that a $250 \mathrm{mg}$ dose was better tolerated than $500 \mathrm{mg}$, and at even lower dose more than $40 \%$ of patients enjoyed symptomatic improvement. Another trial (ISEL) showed interesting pharmacogenomic results. Patients of Asian origin demonstrated a significantly higher response rate as compared to Caucasians [23; personal communication Dr Alex Chang]. Indian patients also showed good benefit, even among males and smokers - groups that were initially thought to be refractory to gefitinib (unpublished data).

Gefitinib has also been tried in combination with docetaxel, with promising early results. Disease control (partial response plus stable disease) was seen in 63\% of those receiving gefitinib combined with docetaxel compared with $32 \%$ for docetaxel alone [24]. Gefitinib may also have a role in recurrent or metastatic head and neck cancer [25] as well as with chemoradiotherapy [26]. High complete response (CR) rates (88\%) and lack of synergistic toxicity with chemoradiotherapy show that this is a promising approach.
Cetuximab : This chimeric human and murine monoclonal antibody that competitively binds to the extracellular domain of EGFR is approved for the treatment of advanced colorectal cancer (in combination with chemotherapy) and has also shown activity in squamous cell carcinoma of head and neck. In advanced colorectal cancer, single-agent cetuximab has produced a partial response in $9 \%$ to $11.6 \%$ of patients and stable disease in $21.6 \%$ to $36.8 \%$. In irinotecan-resistant disease, the combination of cetuximab and irinotecan has resulted in partial responses in $17 \%$ to $22.9 \%$ of patients and stable disease in $31 \%$ to $32.6 \%$ [27].

In squamous cell carcinoma of head and neck it is used in recurrent/metastatic setting. In a recently published trial its concurrent use with radiation showed a median duration of locoregional control of 24.4 months among patients treated with cetuximab plus radiotherapy and 14.9 months among those given radiotherapy alone which is statistically significant [28].

Bevacizumab: Bevacizumab is a recombinant humanized $\mathrm{mAb}$, approved as a first-line therapy for treating metastatic colorectal cancer. In a phase III study irinotecan, 5-fluorouracil, leucovorin (IFL) plus bevacizumab ( $5 \mathrm{mg} / \mathrm{kg}$ every 2 weeks) was compared with IFL plus placebo [29]. The median duration of overall survival was found 20.3 months for those in the bevacizumab group and 15.6 months in the placebo group $(\mathrm{P}<.001)$.

Sorafenib: Sorafenib tosylate was approved in December 2005 for use in advanced renal cell carcinoma. It is an multikinase inhibitor and able to decrease tumour growth and angiogenesis. Its approval is based on a phase III trial [30] which showing that treatment with sorafenib doubled median progression-free survival (PFS) relative to placebo.

Sunitinib maleate: In January 2006, sunitinib malate was approved for treatment of gastrointestinal stromal tumour (GIST) after disease imatinib mesylate failure as well as for the treatment of metastatic renal cell carcinoma. It is also a multikinase inhibitor targeting several receptor tyrosine kinases.

\section{Conclusion}

The cancer cell is a perpetual teacher. Just as conventional chemotherapy was reaching its limits, we now have additional information that leads to a newer option - Targeted therapy. The potential benefits to the patients are so enormous that most major multinational pharmaceutical pipelines are chockablock with such molecules and several exciting ones are already into phase III studies. Efficacy of molecules used in targeted therapy needs to be evaluated differently. The benefit to patients usually does not occur with dramatic tumour 
shrinkage rather it is with respect to overall survival and symptom control. Also the therapeutic window can be much larger that with conventional chemotherapeutic drugs.

\section{Conflicts of Interest \\ None identified}

\section{References}

1. Köhler G \& Milstein C. Continuous cultures of fused cells secreting antibody of predefined specificity. Nature 1975; 256 : 495-7.

2. Egen JG, Kuhns MS, Allison JP CTLA-4.New insights into its biological function and use in tumour immunotherapy. Nat Immunol 2002; 3: 611-8.

3. Sanderson K, Scotland R, Lee P et al. Autoimmunity in a phase I trial of a fully human anti-cytotoxic T-lymphocyte antigen-4 monoclonal antibody with multiple melanoma peptides and Montanide ISA 51 for patients with resected stages III and IV melanoma. J Clin Oncol 2005; 23:741-50.

4. Wu AM, Senter PD. Arming antibodies: prospects and challenges for immunoconjugates. Nat Biotechnol. 2005 Sep; 23:1137-46.

5. Henner W, Figlin R, Garland L et al. Phase 2 Study Tlk286 (GST P11 Activated Glutathione Analog) Advanced Non-Small Cell Lung Cancer (NSCLC). Proc Am Soc Clin Oncol 2002; $1249 \mathrm{a}$

6. Villar GA, Esteller M. Histone deacetylase inhibitors: understanding a new wave of anticancer agents. Int J Cancer 2004; 112: 1718.

7. Karagiannis TC, El-Osta A. Modulation of cellular radiation responses by histone deacetylase inhibitors. Oncogene. 2006; doi 10.1038/sj.onc.1209417.

8. Lasa O, Izu R, Acebo E, Eguino P, Diaz-Perez JL: Treatment of cutaneous T-cell lymphomas with bexarotene. Actas Dermosifiliogr. 2005 Dec; 96: 669-73.

9. Sandler AB, Dubinett SM. COX-2 inhibition and lung cancer. Semin Oncol 2004; 31: 4552.

10. Swisher SG, Roth JA, Nemunaitis J et al. Adenovirus-mediated p53 gene transfer in advanced non-small-cell lung cancer. J Natl Cancer Inst 1999; 91: 763-71

11. Reff ME, Hariharan K, Braslawsky G. Future of monoclonal antibodies in the treatment of haematological malignancies. Cancer Control 2002; 9: 152-66.

12. Feugier P, Van Hoof A, Sebban C, et al. Long-term results of the R-CHOP study in the treatment of elderly patients with diffuse large B-cell lymphoma. J Clin Oncol 2005; 23 : 4117-126.

13. Sievers EL, Linenberger M. Mylotarg. Antibody-targeted chemotherapy comes of age. Curr Opin Oncol 2001; 13:522-7.

14. Keating MJ, Flinn I, Jain V, et al. Therapeutic role of alemtuzumab (Campath-1H) in patients who have failed fludarabine: Results of a large international study. Blood 2002; 99 : 3554-61.

15. Lundin J, Kimby E, Bjorkholm M, et al. Phase II trial of subcutaneous anti-CD52 monoclonal antibody alemtuzumab (Campath-1H) as first-line treatment for patients with B-cell chronic lymphocytic leukaemia (B-CLL). Blood 2002; 100: 768-73.
16. Witzig TE. Efficacy and safety of $90 \mathrm{Y}$ ibritumomab tiuxetan (Zevalin) radio-immunotherapy for non-Hodgkin's lymphoma. Semin Oncol 2003; 30 (6 Suppl ):11-6.

17. Fisher RI, Kaminski MS, Wahl RL et al. Tositumomab and iodine-131 tositumomab produces durable complete remissions in a subset of heavily pretreated patients with low-grade and transformed non-Hodgkin's lymphomas. J Clin Oncol 2005; 20: 7565-73.

18. Roumiantsev S, Shah NP, Gorre ME, et al. Clinical resistance to the kinase inhibitor STI-571 in chronic myeloid leukemia by mutation of Tyr-253 in the Abl kinase domain P-loop. Proc Natl Acad Sci U S A. 2002; 99: 10700-5

19. Richardson P, Sonneveld P, Schuster MW, et al. Bortezomib vs. Dexamethasone in relapsed multiple myeloma: A phase 3 randomized study. Proc Annu Meet Am Soc Clin Oncol. 2004; 22:14S. Abstract 6511.

20. Vogel CL, Cobleigh MA, Tripathy D et al. Efficacy and safety of trastuzumab as a single agent in first-line treatment of HER2overexpressing metastatic breast cancer. J Clin Oncol 2002; 20:719-26.

21. Fukuoka M, Yano S, Giaccone G et al. Multi-institutional randomized phase II trial of gefitinib for previously treated patients with advanced non-small-cell lung cancer. J Clin Oncol 2003; 21: 223746

22. Kris MG, Natale RB, Herbst RS et al. Efficacy of gefitinib, an inhibitor of the epidermal growth factor receptor tyrosine kinase, in symptomatic patients with non-small cell lung cancer: a randomized trial. JAMA 2003; 290: 2149-58.

23. Thatcher N, Chang A, Parikh P et al: Gefitinib plus best supportive care in previously treated patients with refractory advanced non-small-cell lung cancer: results from a randomised, placebo-controlled, multicentre study (Iressa Survival Evaluation in Lung Cancer). Lancet 2005; 366:1527-37.

24. Robinet $\mathrm{G}$, Berard $\mathrm{H}$, Chouaid $\mathrm{C}$ et al. A phase II trial of docetaxel alone and in combination with gefitinib as second-line chemotherapy for patients with non-small cell lung cancer. Ann Oncol 2004; 15 Suppl. $3: 183$

25. Cohen EE, Rosen F, Stadler WM, et al. Phase II trial of ZD1839 in recurrent or metastatic squamous cell carcinoma of the head and neck. J Clin Oncol 2003; 21 : 1980-1987.

26. Cohen E, Haraf D, Stenson K, et al. Integration of gefitinib (G), into a concurrent chemoradiation (CRT) regimen followed by $G$ adjuvant therapy in patients with locally advanced head and neck cancer (HNC) - a phase II trial. Proc Am Soc Clin Oncol 2005; 23 : 501s. 5506

27. Chong G, Cunningham D: The role of cetuximab in the therapy of previously treated advanced colorectal cancer. Semin Oncol. 2005 Dec; 32 (6 Suppl 9):S55-8

28. James AB, Paul MH, Jordi et al. Radiotherapy plus Cetuximab for Squamous Cell Carcinoma of the Head and Neck. N Engl J Med 2006; 354 : 567-78.

29. Hurwitz H, Fehrenbacher L, Novotny W, et al. Bevacizumab plus irinotecan, fluorouracil, and leucovorin for metastatic colorectal cancer. N Engl J Med. 2004; 350 : 2335-42.

30. Patel PH, Chaganti RS, Motzer RJ. Targeted therapy for metastatic renal cell carcinoma. Br J Cancer. 2006 Feb 7; doi:10.1038/sj.bjc.6602978 www.bjcancer.com. 